\title{
QUALIDADE DAS ÁGUAS DOS CÓRREGOS URBANOS DE PRESIDENTE PRUDENTE: ANÁLISE PRELIMINAR
}

\author{
Gabriel Coimbra Rabelo ${ }^{1}$
}

José Biscaíno Neto²

Rosane Freire ${ }^{3}$

\begin{abstract}
RESUMO
Este trabalho teve por objetivo de investigar a influência da urbanização nas águas da Bacia Hidrográfica do Limoeiro, considerando a porção localizada no município de Presidente Prudente SP. O enfoque do presente estudo foi a construção de um banco de dados, organizado espacial e temporalmente, contendo informações sobre diversos parâmetros de qualidade das águas da área de estudo, como forma de apoiar o gerenciamento dos recursos hídricos e contribuir para a elaboração de propostas que favoreçam melhorias nas condições de saneamento ambiental da cidade. As concentrações dos parâmetros foram comparadas com os padrões estabelecidos pelas Resoluções CONAMA 357/2005 e 430/2011. A situação mais crítica foi encontrada para o parâmetro Coliformes Fecais e também para o Fósforo, sobretudo no ponto próximo aos frigoríficos e curtume. Há necessidade de investimentos no tratamento de efluentes e de medidas para reduzir a poluição pontual e difusa.
\end{abstract}

PALAVRAS-CHAVE: Águas urbanas. Poluição difusa. Bacia hidrográfica.

\section{WATER QUALITY OF STREAMS SAGE PRESIDENT OF URBAN: PRELIMINARY ANALYSIS}

\begin{abstract}
This work aimed to investigate the influence of urbanization in the waters of Watershed Limoeiro, considering the part located in the Presidente Prudente city in São Paulo state. The focus of this study was to build a database, organized spatially and temporally, containing information about various parameters of quality of the waters in study area, to support the water management resources and contribute to elaboration of proposal that promote improvements in environmental sanitation conditions in the city. The parameter concentrations were compared to the standards established by

\footnotetext{
${ }^{1}$ Graduação em Engenharia Ambiental, UNESP-FCT. E-mail: gabriel.crsp@gmail.com

${ }^{2}$ Graduação em Engenharia Ambiental, UNESP-FCT. E-mail: josebiscainoneto@hotmail.com

${ }^{3}$ Engenheira Ambiental. Professora Assistente Doutora, UNESP-FCT. E-mail: rosane@fct.unesp.br
} 
Revista Nacional de

Gerenciamento de Cidades

Resolution CONAMA 357/2005 and 430/2011. The most critical situation was found for Fecal Coliforms parameter and also for phosphorus, especially at the point next to refrigerators and tannery. There is need for investment in wastewater treatment and measures to reduce point source and diffuse pollution.

KEYWORDS: Urban waters. Diffuse pollution. Watershed.

\title{
CALIDAD DEL AGUA DE ARROYOS SAGE PRESIDENTE DE URBANA: ANÁLISIS PRELIMINAR
}

\begin{abstract}
RESUMEN
Este estudio tuvo como objetivo investigar la influencia de la urbanización en las aguas de la cuenca hidrográfica del Limoeiro, teniendo en cuenta la parte situada en el municipio de Presidente Prudente - SP. El objetivo de este estudio fue la de construir una base de datos, organizada espacial y temporalmente, que contiene información sobre diversos parámetros de calidad de las aguas de la zona de estudio, con el fin de apoyar la gestión de los recursos hídricos y contribuir a la preparación de propuestas, proporcionando mejoras en las condiciones de saneamiento ambiental de la ciudad. Las concentraciones de los parámetros se compararon con las normas establecidas por la Resolución CONAMA 357/2005 y 430/2011. La situación más crítica se encontró para el parámetro Coliformes fecales y también para el fósforo, sobre todo en el punto más próximo a los frigoríficos y curtiembres. Hay una necesidad de inversión en tratamiento de aguas residuales y las medidas para reducir la contaminación puntual y difusa.
\end{abstract}

PALABRAS CLAVE: Agua urbana. La contaminación difusa. Cuenca hidrográfica.

\section{INTRODUÇÃO}

O ecossistema urbano é um dos ambientes que é mais alterado devido à ação humana. Mas, quem sofre no final do processo de transformação é o próprio homem, responsável pela alteração, que, após ter degradado o meio o qual habita, tem que conviver com os inúmeros problemas devido ao planejamento inadequado (CAMARGO, 2007). De acordo com Maracci (2010), um desses problemas, é a falta de água limpa.

Tucci (2008) define águas urbanas como sendo o sistema que engloba o abastecimento de água e esgotos sanitários, a drenagem urbana, as inundações ribeirinhas e a gestão dos sólidos totais. Sabe-se que as redes de drenagem urbana possuem papel fundamental no transporte de cargas poluidoras. Esta poluição é 


\section{Revista Nacional de}

diversificada e varia de acordo com: uso e ocupação do solo, densidade populacional, geologia e da intensidade e frequência das precipitações (BRITES E GASTALDINI, 2007).

A carga poluidora difusa tem como principal característica uma localização que abrange uma determinada área. Segundo o trabalho de Giansante (2006), as cargas poluidoras difusas têm gerado maior preocupação a diversas entidades científicas internacionais, devido ao seu grande potencial poluidor, chegando duas ou até três vezes maiores que as pontuais.

As atuais formas de utilização e poluição da água têm ameaçado a sustentabilidade ambiental desse recurso, tanto do ponto quantitativo como também do qualitativo. A crise da água está englobada em uma abordagem maior que a crise ambiental mundial, sendo esta de aspecto complexo e multidimensional, estando submetida a diversos posicionamentos de ordem moral, intelectual e ético. Atualmente, ainda persiste uma falsa concepção que a água é um recurso infinito e abundante. Mas, essa falsa concepção fica clara quando se analisa a quantidade e qualidade de água doce distribuída espacialmente (ALVES, 2004). De acordo com Rogers et al. (2006), no século XXI não há nenhuma crise de água, na verdade existe uma evidente crise no gerenciamento dos recursos hídricos.

No Brasil, foram criadas leis para regulamentar o uso e a proteção da qualidade da água, umas dessas leis é a Resolução do Conselho Nacional do Meio Ambiente (CONAMA) n० 357 (BRASIL, 2005) que define os critérios para a classificação dos corpos de água e os padrões de lançamento de efluentes.

Nesse sentido, este trabalho investigou a influência da urbanização nas águas da bacia hidrográfica do córrego do Limoeiro localizado em Presidente Prudente - SP, aproximando os aspectos das características de qualidade de água à ocupação urbana. $O$ intuito maior foi gerar informações, organizadas espacial e temporalmente, que possa subsidiar ações dos órgãos ambientais, da prefeitura municipal, do Comitê de Bacia Hidrográfica e, especialmente, ações da população de Presidente Prudente para redução da poluição hídrica. 


\section{Revista Nacional de}

\section{OBJETIVOS}

O objetivo principal desse trabalho foi avaliar a qualidade da água na porção urbana da bacia hidrográfica do córrego do Limoeiro, com a finalidade de identificar as possíveis relações entre as fontes de poluição hídrica e o uso e ocupação do solo.

\section{METODOLOGIA / MÉTODO DE ANÁLISE}

\subsection{Caracterização da área de estudo}

De acordo com o Instituto Brasileiro de Geografia e Estatística (IBGE) (2010) o local de estudo encontra-se em uma área densamente urbanizada do município de Presidente Prudente - SP, no qual possui cerca de 207.610 habitantes. O município encontra-se em forte desenvolvimento como pode ser notado por meio do crescimento do Produto Interno Bruto (PIB) que, no ano de 2011, aumentou cerca de 10\% em relação ao registrado em 2010 (IBGE, 2013). Para se ter uma ideia o quanto foi elevado o crescimento do PIB no município, nesse mesmo intervalo de tempo o Brasil cresceu apenas 2,7\% (IBGE,2012).

Em relação à geologia, Presidente Prudente encontra-se em domínio da Formação Adamantina, pertencente ao Grupo Bauru, localizado na Bacia do Paraná (SOARES, 2012; DIBIESO,2007; NUNES, 2002). De acordo com o Instituto de Pesquisas Tecnológicas (IPT) (1981a) esse domínio é constituído por: "Arenitos finos e muito finos, podendo apresentar cimentação e nódulos carbonáticos com lentes de siltitos arenosos e argilitos ocorrendo em bancos maciços, estratificação plano-paralela e cruzada de pequeno a médio porte.".

Geomorfologicamente, Presidente Prudente encontra-se no Planalto Ocidental Paulista (IPT, 1981b), possuindo como principais características o relevo levemente ondulado, predominando colinas amplas e baixas com topos aplanados (ROSS E MOROZ, 1993). 


\section{Revista Nacional de}

O clima da Bacia Hidrográfica do Limoeiro, de acordo com a classificação climática de Köppen, é do tipo "Aw" (clima tropical com estação de seca no inverno), havendo como característica a temperatura do mês mais frio ser maior que $18 \stackrel{\circ}{\circ}$, e do mês mais quente ser superior a $22^{\circ} \mathrm{C}$, com estação chuvosa no verão e seco no inverno (SOARES, 2012).

A região de Presidente Prudente encontra-se no Bioma Mata Atlântica. Esse bioma localiza-se em toda a faixa continental atlântica Leste brasileira indo em direção ao Sudeste e Sul do Brasil, é caracterizado pela vegetação florestal predominante e relevo diversificado. Ocorre o predomínio de florestas estacionárias semideciduais, havendo como principal característica o fato que 20 a $50 \%$ das árvores perdem as folhas no período seco do ano (IBGE, 2004).

O histórico de ocupação de Presidente Prudente é caracterizado primeiramente pela ocupação dos topos, seguida pela ocupação das vertentes e por último aos fundos de vale. Essa configuração originou sérios problemas ambientais, no qual se pode destacar: aterro de nascentes, ocupação das áreas de proteção permanentes (APPs), elevação do escoamento superficial por conta da impermeabilização do solo, enchentes e inundações por conta das canalizações (fechadas ou abertas) dos cursos d'água e da ocupação irregular, entre outros (SILVA, 2011).

De acordo com Maracci (2010), em Presidente Prudente - SP ocorreu um crescimento desordenado, no qual acabou proporcionando impactos ambientais profundos aos recursos hídricos, afetando assim a população e sua qualidade de vida.

\subsection{Levantamentos de campo}

Foram escolhidos 5 pontos amostrais estratégicos, envolvendo, principalmente, a área urbanizada da bacia hidrográfica do córrego do Limoeiro. Esses pontos foram selecionados considerando as potenciais fontes de poluição 


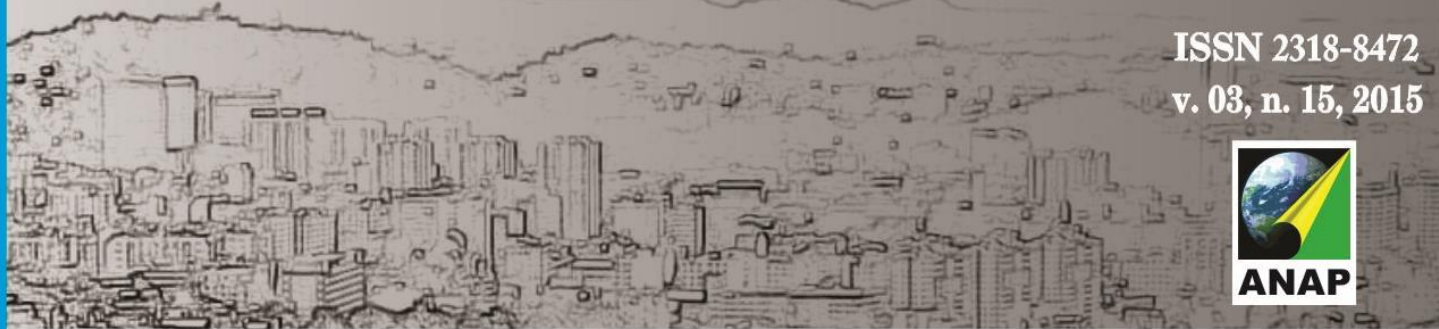

\section{Revista Nacional de}

Gerenciamento de Cidades

bem como o aspecto de acessibilidade. A Figura 1 mostra a distribuição espacial dos pontos amostrais na limitação da bacia, sobreposta a uma imagem Landsat 8 de 15/01/2015 (USGS, 2015).

Figura 1: Pontos amostrais

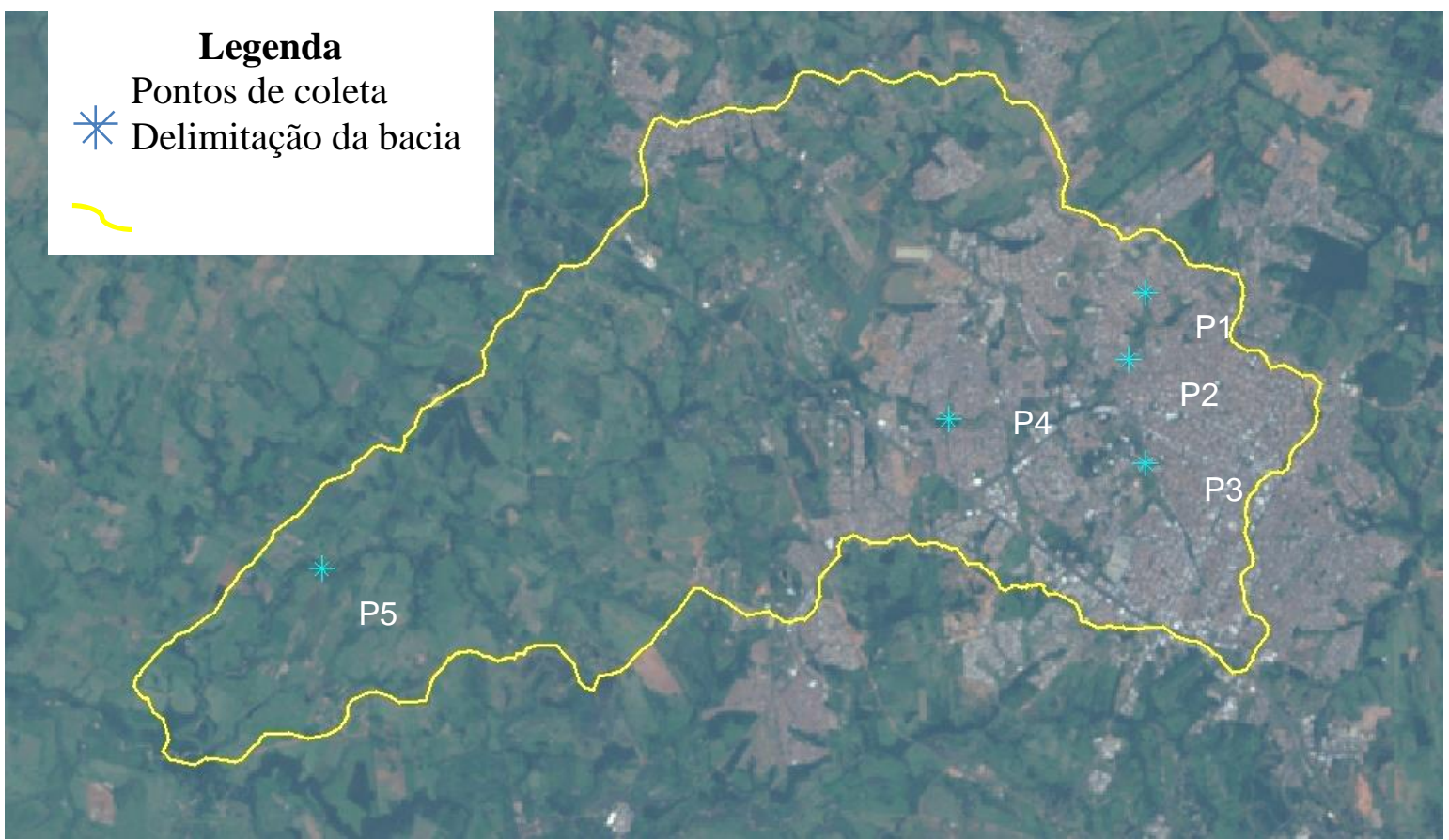

Fonte: SPRING, 2015.

Os pontos P1 e P2 situam-se no Córrego Colônia Mineira, respectivamente, no bairro Parque Residencial São Lucas e no bairro Jardim Belo Horizonte. O P1 se situa o mais próximo da nascente, o mesmo foi escolhido de forma estratégica para avaliar a qualidade da água próxima a nascente. O P2 foi escolhido por estar em uma área residencial podendo, dessa forma, verificar a influência da urbanização na alteração da qualidade da água. O córrego se encontra com leito impermeabilizado, como apresentado na Figura 2 e 3. 


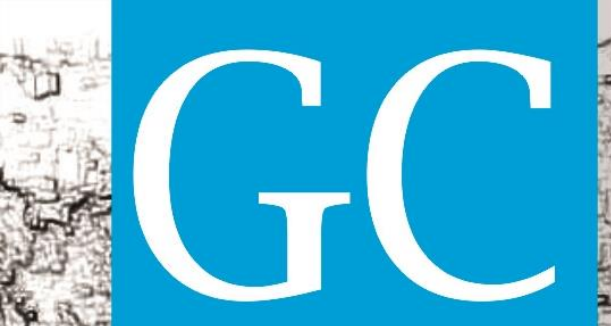

\section{Revista Nacional de Gerenciamento de Cidades}

Figura 2: Ponto de amostragem P1

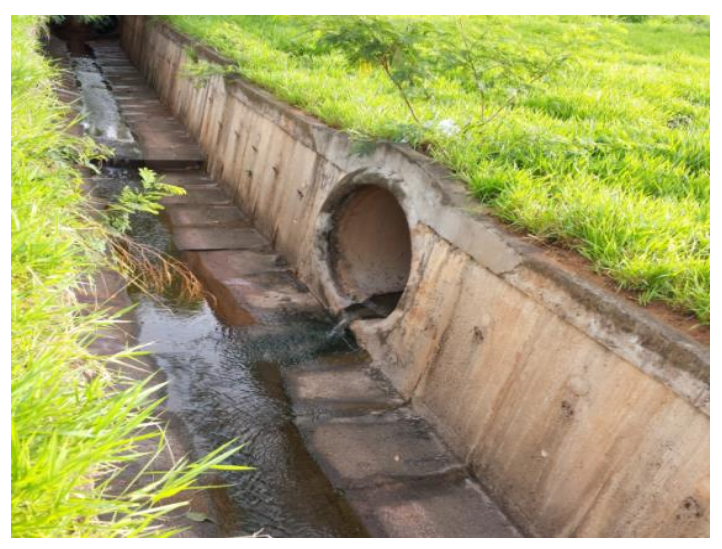

Fonte: AUTOR, 2014.
Figura 3: Ponto de amostragem P2

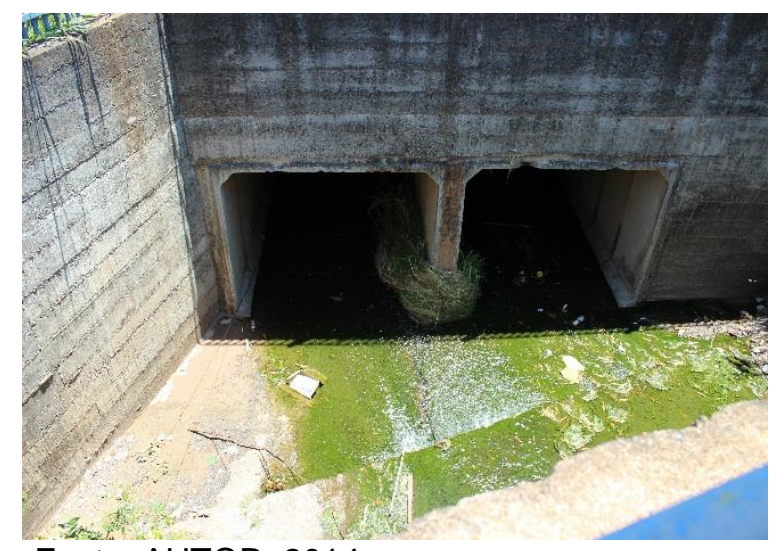

Fonte: AUTOR, 2014.

O ponto P3 situa-se no Córrego do Veado, no Parque do Povo. Ele foi escolhido para avaliar a influência da presença da atividade comercial na qualidade da água no córrego. Esse córrego também possui o leito canalizado, como observado na Figura 4.

O ponto P4 se encontra no bairro Jardim São Gabriel, trata-se ainda do Córrego do Veado, mas em uma porção com forte presença industrial. Ele foi escolhido para verificar a influência do lançamento de efluentes de dois frigoríficos e um curtume na qualidade da água. Nesse trecho, o córrego está com seu leito impermeabilizado, como apresentado na Figura 5.

Figura 4: Ponto de amostragem P3

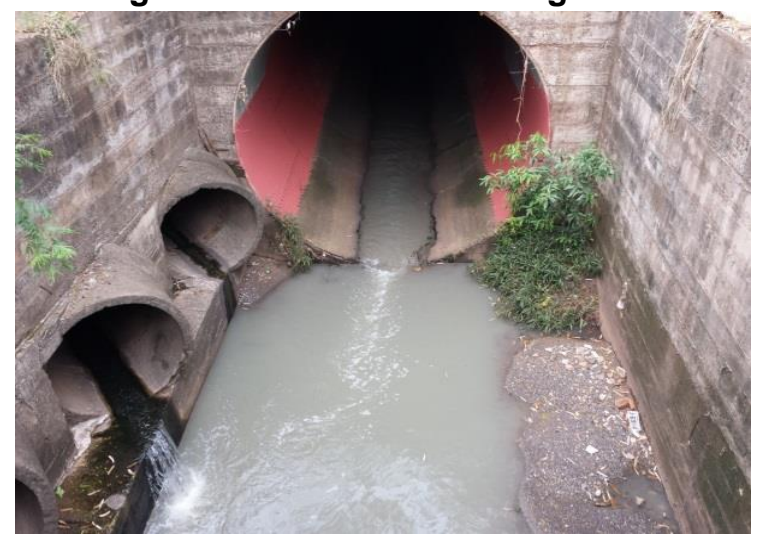

Figura 5: Ponto de amostragem P4

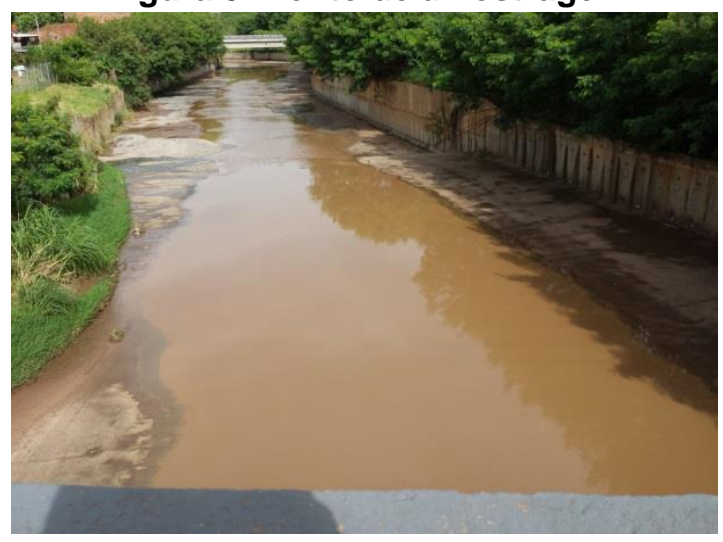

Fonte: AUTOR, 2014. 


\section{Revista Nacional de Gerenciamento de Cidades}

O ponto P5 está localizado na Estrada Municipal para Coronel Goulart, no Córrego do Limoeiro. Ele é o único ponto que não está inserido na malha urbana e que está a jusante da Estação de Tratamento de Esgoto (ETE). Esse córrego está em seu leito natural, como pode ser observado na Figura 6.

Figura 6: Ponto de amostragem P5

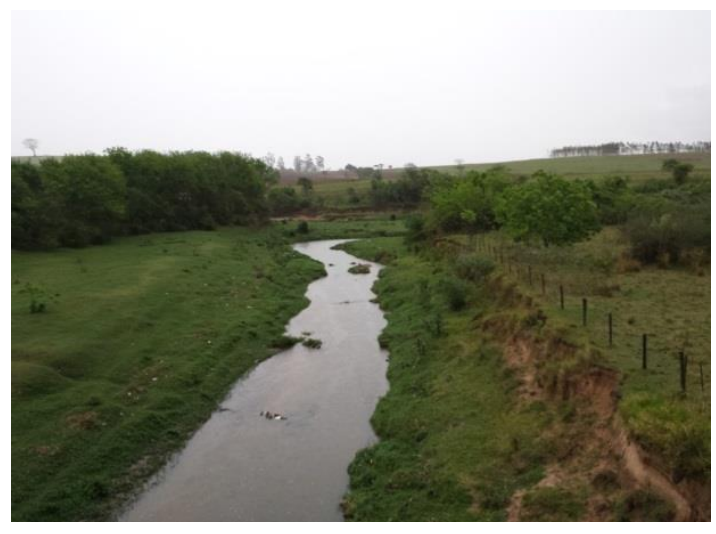

Fonte: AUTOR, 2014.

\subsection{Análise da qualidade de água}

As coletas de amostras de água foram realizadas nos seguintes períodos: novembro/2014 (manhã), janeiro/2015 (tarde) e março/2015 (tarde). Nos pontos P2, P3 e P4 a coleta de água foi feita utilizando um balde e uma corda. Já nos pontos P1 e P5, devido a grande facilidade de acesso ao corpo d'água, as amostras foram coletadas diretamente no canal. Em todos os casos, procurou-se coletar a água no leito vazante, na seção central do curso d'água.

Foram realizadas análises laboratoriais para a verificação de nove parâmetros físico-químicos e biológicos de qualidade de água, tais como: Coliformes Fecais (NMP/100 ml), Potencial Hidrogeniônico $(\mathrm{pH})$, Demanda Bioquímica de Oxigênio $\left(\mathrm{DBO}_{5}-\mathrm{mg} / \mathrm{L}\right)$, Nitrogênio Total Kjeldahl (NTK - mg/L), Fósforo Total $(\mathrm{mg} / \mathrm{L})$, Temperatura $\left({ }^{\circ} \mathrm{C}\right)$, Turbidez (NTU), Sólidos Dissolvidos Totais $(\mathrm{mg} / \mathrm{L})$ e 


\section{Revista Nacional de}

Oxigênio Dissolvido (OD - mg/L). As análises seguiram os procedimentos analíticos descritos em APHA (1998).

As amostras coletadas foram armazenadas em garrafas de Politereftalato de etileno (PET), com capacidade de $2 \mathrm{~L}$, e em recipiente de vidro âmbar, de $250 \mathrm{~mL}$. Ambos foram limpos previamente, conforme recomendação descrita em literatura, e acondicionados em uma caixa de isopor com gelo para transporte.

In loco foram realizadas a medição da temperatura $(T)$ e a do Oxigênio Dissolvido (OD), utilizando termômetro de mercúrio e oxímetro HANNA (HI 9146), respectivamente. As outras variáveis físicas, químicas e biológicas foram analisadas na Central de Laboratórios da Faculdade de Ciências e Tecnologia de Presidente Prudente - FCT/UNESP. Além disso, foi adquirido dados relevantes da área de estudo na Estação Meteorológica da FCT/UNESP.

Os dados coletados foram tratados em planilhas eletrônicas para a realização de cálculos e geração de gráficos para a avaliação da qualidade da água. Para isso, foi utilizado o software Microsoft Office Excel.

Os resultados foram discutidos a luz da Resolução CONAMA no 357/2005. De acordo com o Decreto Estadual ㄲo 10.755/1977, que dispõe sobre o enquadramento dos corpos d'água no Estado de São Paulo, os pontos P1 e P2 são classificados como classe 2, enquanto que os demais pontos são classificados como classe 4. Como a referida resolução estabelece apenas valores de concentração de $\mathrm{OD}$ e do $\mathrm{pH}$ entre os parâmetros avaliados para classe 4 , em relação aos aspectos de discussão, para os pontos P3, P4 e P5 foram utilizados os limites estabelecidos para a classe 3 .

Na Tabela 1 abaixo, constam alguns parâmetros de qualidade de água doce, e os respectivos padrões de qualidade estabelecidos pela Resolução CONAMA 357/2005 variando em função da classe de uso da água. 
Revista Nacional de

Gerenciamento de Cidades

Tabela 1: Padrões de qualidade da água

\begin{tabular}{c|c|c|c}
\hline Parâmetros & Classe 2 & Classe 3 & Classe 4 \\
\hline OD (mg/L) & $\geq 5,0$ & $\geq 4,0$ & $\geq 2,0$ \\
\hline Coliformes Fecais (NMP/100mL) & $\leq 1000$ & $\leq 4000$ & - \\
\hline $\mathrm{pH}$ & Entre 6 e 9 & Entre 6 e 9 & Entre 6 e 9 \\
\hline DBO (mg/L) & $\leq 5,0$ & $\leq 10,0$ & - \\
\hline Turbidez (UNT) & $\leq 100$ & $\leq 100$ & - \\
\hline Sólidos Totais (mg/L) & $\leq 500$ & $\leq 500$ & - \\
\hline Fósforo Total (mg/L) (Lótico) & $\leq 0,10$ & $\leq 0,15$ & - \\
\hline
\end{tabular}

Fonte: BRASIL, 2005.

\section{RESULTADOS}

A temperatura é muito importante em relação às taxas de reações químicas e biológicas e na solubilidade dos gases (MANOEL, 2013; ATKINS E JONES, 2011). Na Figura 7 é apresentada a variação da temperatura bem como os valores encontrados nas amostras de água coletadas e a média do ar no período de coleta, com base nos dados da Estação Meteorológica da FCT/UNESP.

Figura 7: Temperatura

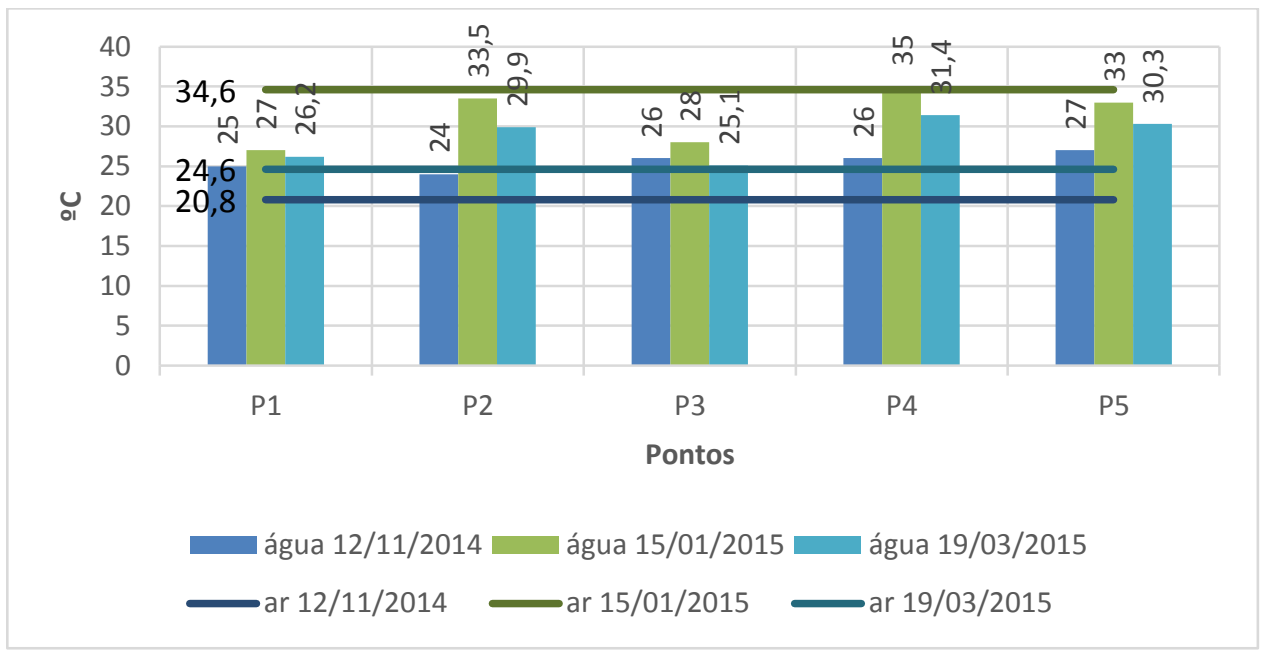

Fonte: AUTOR, 2015. 


\section{Revista Nacional de}

Não houve grandes variações na temperatura da água que poderiam indicar ação antrópica interagindo no meio. Portanto, os lançamentos de efluentes estão de acordo com a Resolução CONAMA 430/2011, uma vez que a temperatura da água não ultrapassou os $40^{\circ} \mathrm{C}$.

De acordo com a Companhia Ambiental do Estado de São Paulo (CETESB) (2004), Um dos principais indicadores do lançamento de efluentes domésticos sem tratamento nos recursos hídricos é o aumento da presença de Coliformes Termotolerantes na água. Na Figura 8 , tem-se os valores encontrados de coliformes fecais nas amostras de água coletadas.

Figura 8: Coliformes Fecais

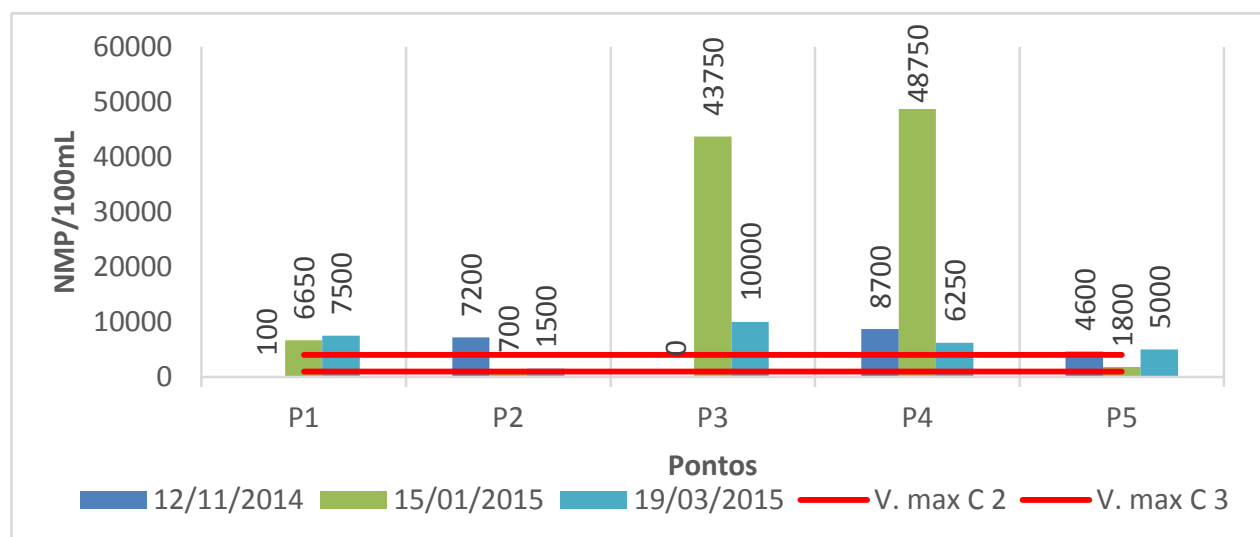

Fonte: AUTOR, 2015.

$\mathrm{Na}$ maioria dos casos, os pontos extrapolaram os valores definidos pela Resolução CONAMA no 357/2005. De maneira geral, o ponto P4 foi o que apresentou os maiores valores para esse parâmetro, isso pode indicar o lançamento de efluentes sem tratamento adequado de animais de sangue quente, principalmente, aves e bovinos, visto que próximo a esse ponto existe dois frigoríficos. O ponto P3 também apresentou resultados nada satisfatórios, isso provavelmente é devido a ligações clandestinas dos comércios e residências circundantes ao local de amostragem. Nesse sentido, maiores investigações são necessárias. 


\section{Revista Nacional de}

De acordo com Fravet (2006), o pH nas águas superficiais pode ser influenciado por diferentes fatores, como, a geologia no qual o curso d'água se encontrar e por possíveis fontes de poluição. Nos ecossistemas aquáticos, a variação do $\mathrm{pH}$ pode influenciar diretamente a fisiologia de várias espécies. Além disso, indiretamente em condições especificas de $\mathrm{pH}$, pode contribuir para a precipitação de elementos químicos tóxicos, por exemplo, metais pesados. Em outras condições, pode interferir na solubilidade de nutrientes (CETESB,2015). $\mathrm{Na}$ Figura 9, tem os valores encontrados de $\mathrm{pH}$ nas amostras de água coletadas.

Figura 9: pH

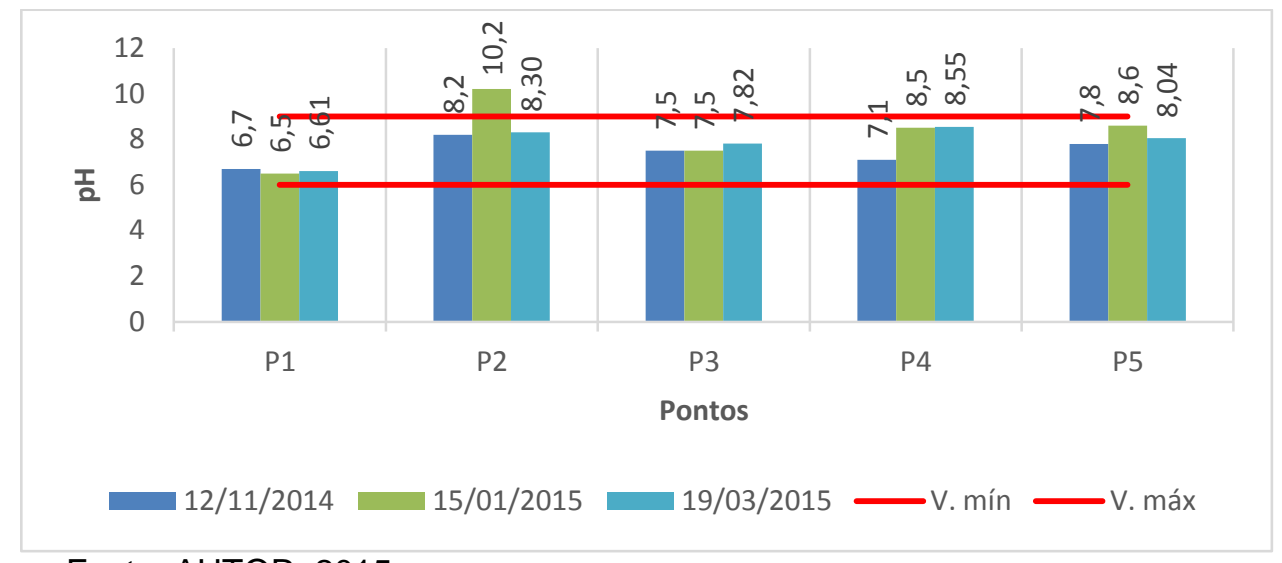

Fonte: AUTOR, 2015.

Todos os trechos monitorados, com exceção do ponto P2 (15/01/2015), ficaram de acordo com os limites estabelecidos pelo instrumento legal. $O$ valor excessivo no P2 leva a suspeitar o lançamento de algum produto de limpeza doméstico no recurso hídrico, como por exemplo, a água sanitária e o sabão, por possuírem um elevado pH (BRASIL, 2009; BRASIL, 1978).

Um elevado valor da $\mathrm{DBO}_{5}$ pode interferir no equilíbrio da vida aquática, além de gerar sabores e odores desagradáveis. Em um caso mais extremo esse elevado valor pode provocar a extinção do oxigênio na água, provocando o desaparecimento de diversas formas de vidas aquáticas (ORTEGA, 2011). Na 


\section{Revista Nacional de Gerenciamento de Cidades}

Figura 10, tem-se os valores de concentração encontrados de DBO nas amostras de água coletadas.

Figura 10: DBO

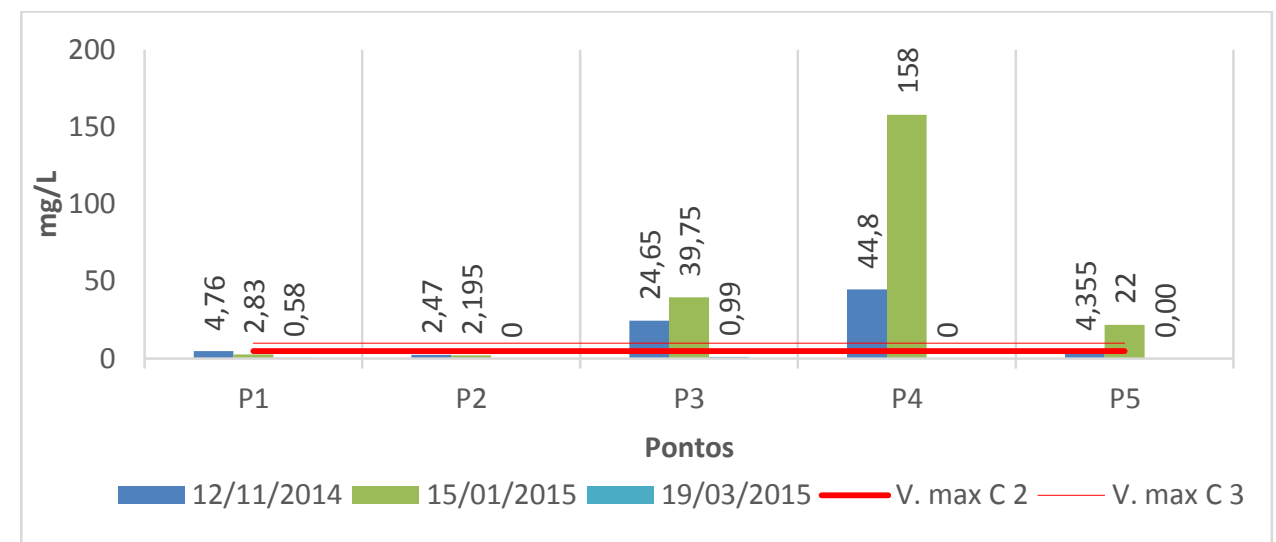

Fonte: AUTOR, 2015.

Em uma primeira avaliação da $\mathrm{DBO}$, apenas os pontos $\mathrm{P} 1$ e $\mathrm{P} 2$ atenderam a legislação, considerando as coletas realizadas. Como já era esperado, a DBO teve os valores mais altos de concentração no ponto $\mathrm{P} 4$. Muito provavelmente essas concentrações estão relacionadas ao lançamento de efluentes dos frigoríficos e do curtume no corpo hídricos. Além disso, ressalta-se que devido à alta concentração encontrada, os efluentes não estão recebendo o tratamento suficientemente adequado. O ponto P3 também teve resultados bastante insatisfatórios e isso, provavelmente, pode ser devido às ligações clandestinas dos comércios ali instalados, pois houve a constatação de espumas e odor de produtos de limpeza.

O nitrogênio pode ser considerado um dos principais elementos na manutenção do equilíbrio dos ecossistemas aquáticos, porque sua participação é essencial na formação de proteínas (CIGLICINAO,2009). Mas, a elevada concentração de nitrogênio pode contribuir para o processo de eutrofização (VALENTE et al., 1997). Na Figura 11, tem os valores encontrados de NTK nas amostras de água coletadas. 


\section{Revista Nacional de}

Gerenciamento de Cidades

Figura 11: NTK

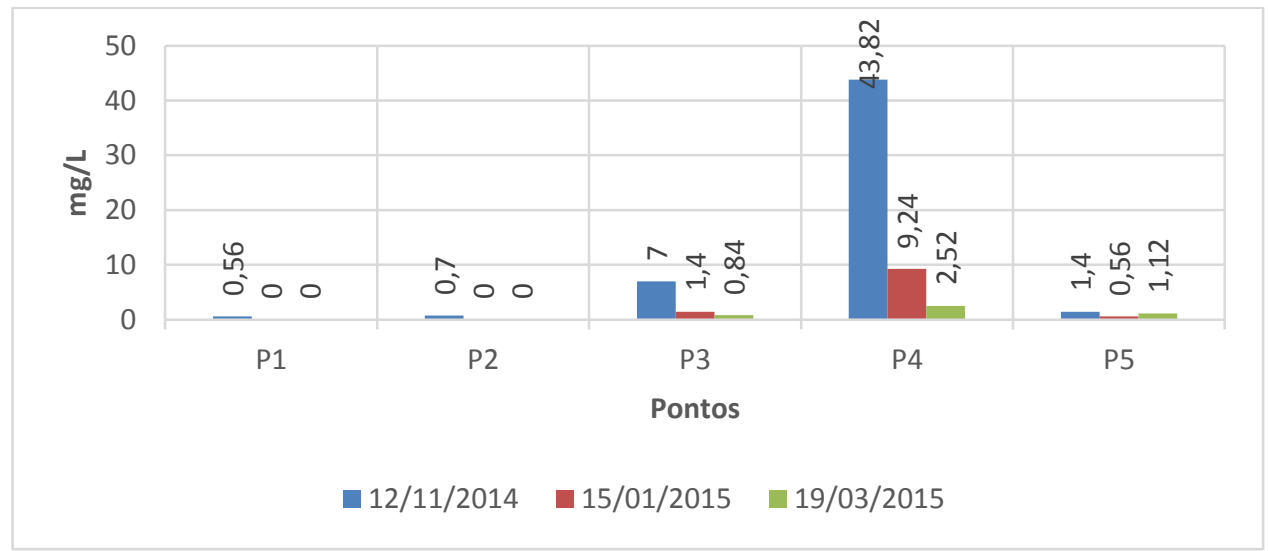

Fonte: AUTOR, 2015.

O ponto $\mathrm{P} 4$ apresentou elevada concentração de nitrogênio quando comparado aos demais. Acredita-se que a origem excessiva de nitrogênio nesse ponto esteja associada aos despejos domésticos e industriais.

O fósforo é um dos principais causadores de eutrofização nos ecossistemas aquáticos. Na Figura 12, tem os valores de concentração de Fósforo Total encontrados nas amostras de água coletadas.

Figura 12: Fósforo Total

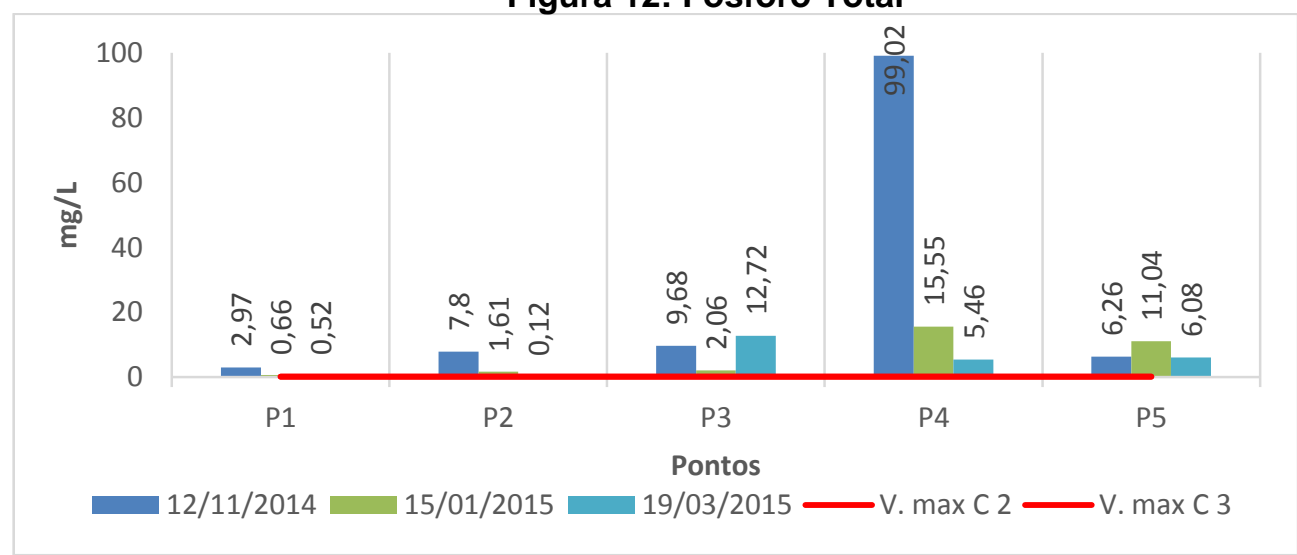

Fonte: AUTOR, 2015.

Em todos os casos, os trechos monitorados extrapolaram o limite máximo de concentração estabelecido pela Resolução para ambientes lóticos. Em especial, o ponto P4 apresentou os mais elevados valores de concentração. Isso pode ser 


\section{Revista Nacional de}

devido a presença dos frigoríficos e do curtume instalados em torno desse curso d'água. De acordo com Minguini (2007), efluentes da indústria de fertilizantes, pesticidas, conservas alimentícias, abatedouros, frigoríficos e laticínios possuem fósforo em quantidade elevada. Além disso, chamou atenção da quantidade fósforo presente no ponto P5. Nesse último trecho, acredita-se o valor obtido seja devido as formas fosfatadas presentes nos efluentes da ETE.

A turbidez em amostras de água é devido a presença de partículas em suspensão, provocando a diminuição da penetração da luz no meio (MOLINA, 2006). Dessa forma, o seu incremento pode influenciar as comunidades biológicas aquáticas negativamente (ORTEGA, 2011). Na Figura 13 tem os valores encontrados de turbidez nas amostras de água coletadas.

Figura 13: Turbidez

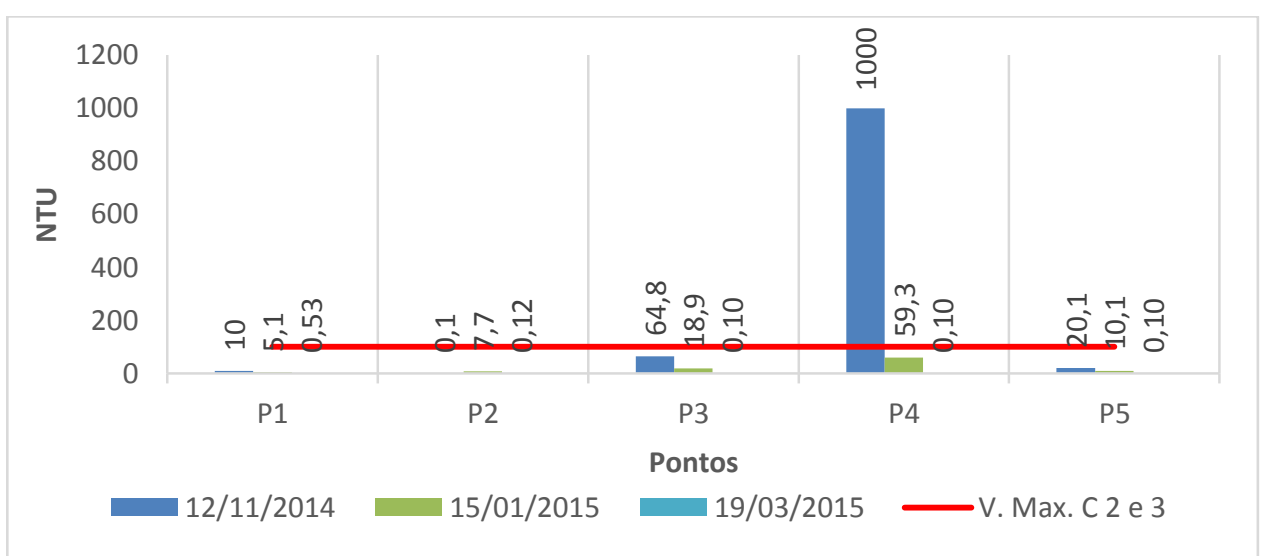

Fonte: AUTOR, 2015.

Na coleta do dia 12/11/2014, foi obtido o maior valor de turbidez para cada ponto quando compara-se com as outras coletas, com exceção do ponto P2. Isso pode ser devido a chuva ocorrida no dia de coleta. De acordo com a Estação Meteorológica da FCT/UNESP nesse dia choveu 4,4 mm. O maior valor de turbidez foi verificado no ponto P4 por conta da presença dos efluentes dos frigoríficos e do curtume somada ao grande volume de água com materiais suspensos decorrente da lavagem superficial, elevando, assim, a turbidez no córrego. 


\section{Revista Nacional de}

Por meio dos valores obtidos para Sólidos Dissolvidos Totais, foi possível verificar a influência direta da presença de materiais carreados pela água da chuva. $\mathrm{Na}$ Figura 14, tem os valores de concentração encontrados de Sólidos Dissolvidos Totais nas amostras de água coletadas.

Figura 14: Sólidos Dissolvidos Totais

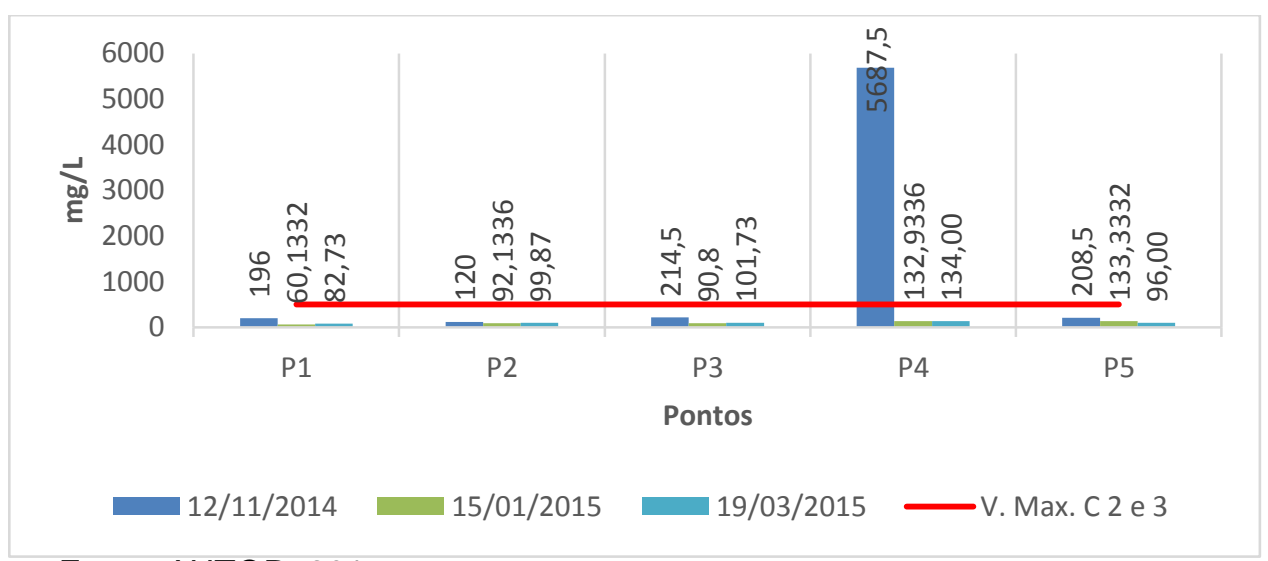

Fonte: AUTOR, 2015.

Todos os trechos monitorados, exceto o ponto P4 (12/11/2014) obtiveram valores que atenderam o limite estabelecido em Resolução. No trecho em exceção, é possível relacionar o valor obtido ao runoff superficial e, possivelmente, a algum encaminhamento de resíduos provenientes das atividades industriais instaladas. Maiores investigações possibilitará a confirmação.

$\mathrm{Na}$ Figura 15, tem os valores de concentração de OD encontrados nas amostras de água coletadas. 
Figura 15: OD

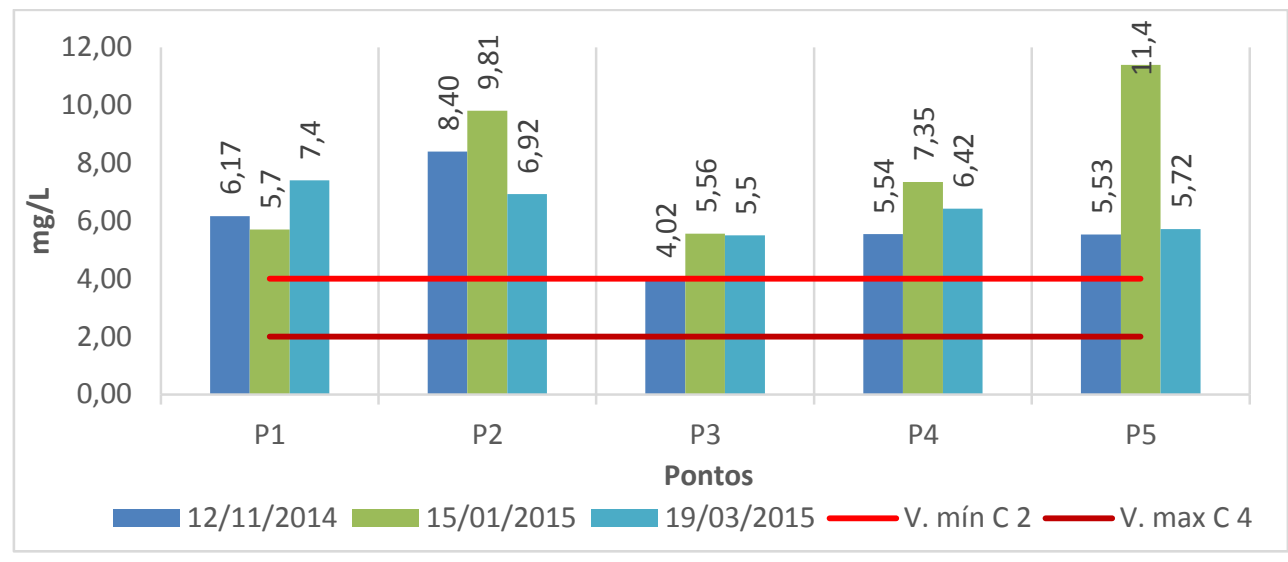

Fonte: AUTOR, 2015.

A média do OD para o ponto P2 apresentou o maior valor quando se compara com os demais pontos, um dos fatores que favorece a oxigenação da água nesse ponto amostral são os degraus ali presentes, porque os mesmos promovem turbulência na água. Enquanto isso, o menor valor do OD foi para o ponto P3, esse efeito pode ser atribuído à decomposição de matéria orgânica provinda de lançamento de efluentes.

Os pontos P1 e P2 atenderam a Resolução. Enquanto que os demais pontos poderiam ser enquadrados em uma classe que não fosse a 4 . Os valores de OD apresentaram resultados satisfatórios, acredita-se que isso foi por conta das coletas terem sido realizadas no período chuvoso. Nessa época a vazão dos cursos d'água é elevada, no qual promove o turbilhonamento das águas, favorecendo a oxigenação daquele meio.

Os resultados obtidos nos trechos estudados indicam a presença de poluição proveniente de fontes pontuais e difusas, que estão modificando drasticamente as características físico-químicas e biológicas da bacia do córrego do Limoeiro. Dessa forma, diante dos resultados obtidos na bacia do córrego do Limoeiro, ficar claro que a área necessita de mais atenção. 


\section{Revista Nacional de}

Gerenciamento de Cidades

\section{CONCLUSÃO}

A comparação dos valores obtidos com os valores estabelecidos pela Resolução CONAMA no 357/2005 permitiu verificar que a qualidade das águas na porção mais urbanizada da bacia hidrográfica do córrego do Limoeiro encontra-se, em sua maior parte, deteriorada, considerando principalmente os seguintes parâmetros: Coliformes Fecais e Fósforo.

Na nascente (P1) e na área residencial (P2) foram encontradas as melhores condições do estado qualidade da água. Verificou-se que o ponto P4 está em uma situação crítica e acredita-se que o comprometimento da qualidade nesse ponto foi devido principalmente aos efluentes dos frigoríficos e curtume. No ponto P5 o principal interferente na qualidade da água está relacionado a proximidade da ETE.

O principal objetivo desse trabalho foi alcançado com êxito, porque por meio dos parâmetros analisados foi possível verificar sua sensibilidade em apresentar alterações ocorridas no meio. Além disso, foi possível identificar os prováveis causadores dessas alterações.

\section{REFERÊNCIAS}

ALVES, A. O. Planejamento ambiental urbano na microbacia do Córrego da Colônia Mineira Presidente Prudente/SP. 2004. 166f. Dissertação (Mestrado em Geografia) - Faculdade de Ciências e Tecnologia, Universidade Estadual Paulista, Presidente Prudente.

APHA. American Public Health Association. Standard methods for the examination of water and wastewater. Washington, D.C, 1998.

ATKINS, P.; JONES, L. Princípios de química: questionando a vida moderna e o meio ambiente. Porto Alegre: Bookman, 2011.

BRASIL. Resolução ANVISA n. 55/2009, de 10 de novembro de 2009. Dispõe sobre Regulamento Técnico para Produtos Saneantes Categorizados como Água Sanitária e Alvejantes à Base de Hipoclorito de Sódio ou Hipoclorito de Cálcio e dá outras providências. Disponível em: < http://portal.anvisa.gov.br/wps/wcm/connect/9cdb1f804ba03ddbb97cbbaf8fded4db/RDC+55_2009.pdf ?MOD=AJPERES $>$. Acesso em: 25 abr. 2015.

BRASIL. Resolução CONAMA n. 357/2005, de 17 de março de 2005. Dispõe sobre a classificação dos corpos de água e diretrizes ambientais para o seu enquadramento, bem como estabelece 


\section{Revista Nacional de}

Gerenciamento de Cidades

as condições e padrões de lançamentos de efluentes, e dá outras providências. Disponível em: < http://www.mma.gov.br/port/conama/res/res05/res35705.pdf>. Acesso em: 16 abr. 2015.

BRASIL. Resolução Normativa ANVISA n. 1/1978, de 27 de novembro de 1978. Aprova as normas a serem obedecidas pelos detergentes e seus congêneres. Disponível em: < http://www.anvisa.gov.br/anvisalegis/resol/01_78.htm>. Acesso em: 25 abr. 2015

BRITES, A. P. Z; GASTALDINI, M. C. C. Avaliação da carga poluente no sistema de drenagem de duas bacias hidrográficas urbanas. Revista Brasileira de Recursos Hídricos, Porto Alegre, v.12, n.4, p. 211-221, out. 2007.

CAMARGO, C. E. S. Qualidade ambiental em Presidente Prudente/SP. 2007. 155f. Dissertação (Mestrado em Geografia) - Faculdade de Ciências e Tecnologia, Universidade Estadual Paulista, Presidente Prudente.

CETESB. Companhia Ambiental do Estado de São Paulo. Potencial Hidrogeniônico (pH). 2015. Disponível em: < http://www.cetesb.sp.gov.br/userfiles/file/agua/aguas-superficiais/aguasinteriores/variaveis/aguas/variaveis_quimicas/potencial_hidrogenionico.pdf>. Acesso em: $05 \mathrm{abr}$. 2015.

CETESB. Companhia Ambiental do Estado de São Paulo. Qualidade das águas superficiais. São Paulo: CETESB, 2014 (2014).

CICIGLIANO, G. D. Avaliação da qualidade da água em piscicultura com sistema de cultivo em tanques-rede no município de Santa Fé do Sul - SP. 2009. 83f. Dissertação (Mestre em Engenharia Civil) - Faculdade de Engenharia de Ilha Solteira, Universidade Estadual Paulista, Ilha Solteira.

DIBIESO, E. P. Planejamento ambiental da Bacia Hidrográfica do Córrego do Cedro Presidente Prudente/SP. 2007. 171f. Dissertação (Mestrado em Geografia) - Faculdade de Ciências e Tecnologia, Universidade Estadual Paulista, Presidente Prudente.

FRAVET, A. M. M. F. de. Qualidade da água utilizada para irrigação de hortaliças na região de Botucatu - SP e saúde pública. 2006. 83f. Dissertação (Mestrado em Agronomia) - Faculdade de Ciências Agronômicas, Universidade Estadual Paulista, Botucatu.

GIANSANTE, A. E. Avaliação de cargas poluidoras difusas para planejamento ambiental em bacias hidrográficas: aplicação na Bacia do Ribeirão Piraí - SP. São Paulo, 2006.

IBGE. Instituto Brasileiro de Geografia e Estatística. Censo 2010. 2010. Disponível em: <http://www.censo2010.ibge.gov.br/sinopse/index.php?uf=35\&dados=1>. Acesso em: 07 mar. 2015.

IBGE. Instituto Brasileiro de Geografia e Estatística. Em 2011, PIB cresce 2,7\% e totaliza R\$ 4,143 trilhões. $2012 . \quad$ Disponível em: $<h t t p: / / s a l a d e i m p r e n s a . i b g e . g o v . b r / n o t i c i a s ? v i e w=$ noticia\&id=1\&busca=1\&idnoticia=2093>. Acesso em: 01 abr. 2014.

IBGE. Instituto Brasileiro de Geografia e Estatística. IBGE lança o Mapa de Biomas do Brasil e o Mapa de Vegetação do Brasil, em comemoração ao Dia Mundial da Biodiversidade. 2004. Disponível em:<http://www.ibge.gov.br/home/presidencia/noticias/21052004biomashtml.shtm> Acesso em: 27 abr. 2014. 
Revista Nacional de

Gerenciamento de Cidades

IBGE. Instituto Brasileiro de Geografia e Estatística. Produto Interno Bruto dos Municípios - 2011. 2013.

Disponível

em:

<http://www.cidades.ibge.gov.br/xtras/grafico_cidades.php?lang=\&codmun=354140\&idtema=125\&sea rch=sao-paulo|presidente-prudente|produto-interno-bruto-dos-municipios-2011> Acesso em: $01 \mathrm{abr}$. 2015.

IPT. Instituto de Pesquisas Tecnológicas do Estado de São Paulo. Mapa geomorfológico do Estado de São Paulo: 1:1.000.000. São Paulo: IPT, 1981b. v. 2.

IPT. Instituto de Pesquisas Tecnológicas do Estado de São Paulo. Mapa geológico do Estado de São Paulo: 1:500.000. São Paulo: IPT, 1981a. v. 1.

MANOEL, L. O. Avaliação e monitoramento da qualidade da água na microbacia do Córrego Caçula no município de Ilha Solteira - SP. 2013. 167f. Dissertação (Mestre em Engenharia Civil) Faculdade de Engenharia de Ilha Solteira, Universidade Estadual Paulista, Ilha Solteira.

MARACCI, J. G. P. Degradação ambiental e qualidade de vida na microbacia do Córrego do Gramado - Presidente Prudente/São Paulo. 2010. 132f. Monografia (Bacharel em Geografia) Faculdade de Ciências e Tecnologia, Universidade Estadual Paulista, Presidente Prudente.

MINGHINI, I. Avaliação qualitativa da água residuária de abatedouro de aves para fins de reuso em irrigação. 2007. 79f. Dissertação (Mestrado em Agronomia) - Faculdade de Ciências Agronômicas, Universidade Estadual Paulista, Botucatu.

MOLINA, P. M. Diagnóstico da qualidade e disponibilidade de água na microbacia do Córrego Água da Bomba no município de Regente Feijó - SP. 2006. 160f. Dissertação (Mestrado em Engenharia Civil) - - Faculdade de Engenharia de Ilha Solteira, Universidade Estadual Paulista, Ilha Solteira.

NUNES, J. O. R.Uma contribuição metodológica ao estudo da dinâmica da paisagem aplicada a escolha de áreas para a construção de aterro sanitário em Presidente Prudente - SP. 2002. 230 f. Tese (Doutorado em Geografia) - Faculdade de Ciências e Tecnologia , Universidade Estadual Paulista, Presidente Prudente.

ORTEGA, D. J. P. Avaliação dos efeitos das atividades antrópicas na bacia hidrográfica do Córrego do Ipê, município de Ilha Solteira - SP. 2011. 151f. Dissertação (Mestre em Engenharia Civil) - Faculdade de Engenharia de Ilha Solteira, Universidade Estadual Paulista, Ilha Solteira.

ROGERS, P. P.;LLAMAS, M. R.; MATÍNEZ-CORTINA, L. Water Crisis: Myth or Reality? Londres: Taylor \& Francis, 2006.

ROSS, J. L. S; MOROZ, I. C. Mapa geomorfológico do Estado de São Paulo. Revista do Departamento de Geografia, São Paulo, n.10, p.41-56, 1996.

SILVA, L. J. P. da. Estudo sobre depósitos tecnogênicos no entorno da represa da SABESP em Presidente Prudente - SP. 2011. 74f. Monografia (Bacharel em Geografia) - Faculdade de Ciências e Tecnologia, Universidade Estadual Paulista, Presidente Prudente.

SOARES, F. B. Planejamento ambiental da Bacia do Balneário da Amizade - São Paulo. 2012. 153 f. Trabalho de conclusão de curso (Graduação em Geografia) - Faculdade de Ciências e Tecnologia, Universidade Estadual Paulista, Presidente Prudente. 
Revista Nacional de Gerenciamento de Cidades

TUCCI, C. E. M. Águas urbanas. Estudos avançados, v.22, n.63, p.97-112, 2008.

USGS. United States Geological Survey. Landsat 8. 2015. Disponível em: < http://landsat.usgs.gov/landsat8.php>. Acesso em: 01 abr. 2015.

VALENTE, J. P. S; PADILHA, P. M.; SILVA, A. M. M. da. Contribuição da cidade de Botucatu - SP com nutrientes ( fósforo e nitrogênio) na eutrofização da represa de Barra Bonita. Eclet. Quím, v.22, p. 31-48, 1997. 